\title{
APRESENTAÇÃO
}

\section{DOSSIÊ MICHEL FOUCAULT: o pensamento de Michel Foucault em nosso tempo de agora}

\author{
Cristiane Maria Marinho \\ Universidade Estadual do Ceará (UECE) \\ cmarinho2004@gmail.com \\ Dorgival Gonçalves Fernandes \\ Universidade Federal de Campina Grande (UFCG) \\ dorgefernandes@yahoo.com.br \\ Elias Ferreira Veras \\ Universidade Estadual do Ceará (UECE-FAFIDAM) \\ eliashistoria@yahoo.com.br \\ Eduardo F. Chagas \\ Universidade Federal do Ceará (UFC/CNPq) \\ ef.chagas@uol.com.br
}

O que somos? Como nos tornamos o que somos? Quais relações de saber-poder atravessam nossas subjetividades? Quais dispositivos e tecnologías foram/são mobilizados em torno das urgências histórico-contemporâneas? Quais outros somos são possíveis diante das estratégias de governamentalidade disciplinares e biopolíticas que marcam a contemporaneidade? O pensamento de Michel Foucault e seu modo crítico de indagação histórica e filosófica possibilitam que interpelemos os processos que nos fizeram e nos fazem ser quem somos, seus mecanismos de assujeitamento e posibilidades de resistências, nos levando a problematizar os processos de subjetivação como efeitos e indicios de relações de poder-saber historicamente constituídas.

Desse modo, ainda que Foucault tenha produzido em um contexto marcado por especificidades - a Europa ocidental da segunda metade do século XX - o que nos faz atentar para a geopolítica da produção do seu pensamento, suas obras, pensadas pelo filósofo como "caixa de ferramenta", nos ajudam a compreender nosso presente e os mecanismos de saber-poder que nos fazem ser o que somos.

O pensamento foucaultiano, que alia ativismo filosófico, ético e político é inspirador para refletirmos sobre o presente brasileiro, marcado pelas politicas neoliberais de desmonte da universidade pública, pelas tentativas de censura ao 
pensamento crítico, pela articulação despudorada de grupo fascistas ultraconservadores que ameaçam as recentes conquisas democráticas da sociedade brasileira.

Em diálogo com Foucault, podemos refletir, por exemplo, sobre as tecnologías e dispositivos políticos que produzem as subjetividades de normatização, mas, sobretudo, de resistência; a produção discursiva que exercita relações de poder e de saber por meios dos mais diferentes dispositivos; as estratégias de governamentalidade, mas, também as micropoliticas de resistências.

É nesse sentido e nessa direção que apresentamos a seguir os textos que compõem este Dossiê, como radiografias do pensamento foucaultiano hoje, mas também como uma apropriação brasileira dessa caixa de ferramenta que é o pensamento de Michel Foucault.

Daniel Toscano López, Professor Asistente de investigación jurídica (Centro de bioética, Facultad de Medicina, Clínica Alemana) da Universidad del Desarrollo, UDD Chile, nos traz o artigo FOUCAULT: UN MODO PARADÓJICO DE HACER FILOSOFÍA no qual se propõe a caracterizar o modo paradoxal e crítico da indagação filosófica foucaultiana, a qual se dá por rupturas e descontinuidades e na busca de compreender nosso presente e o que somos, indagando pelas tecnologías e dispositivos políticos de poder que produzem nossas subjetidades. O texto se estrutura em três momentos: o primeiro disserta sobre o lugar que ocupam o poder, a subjetividade e a verdade no pensamento foucaultiano; o segundo apresenta o paradoxo e a raridade como características de suas investigações, tendo o carangueijo como a imagen mais próxima de seu pensamento por este não se mover de forma linear; finalmente, o terceiro momento se desenvolve apresentando o elogio da franqueza efetuado por Foucault, cuja imagen emblemática é a figura do parresiasta.

O Professor Dorgival Gonçalves Fernandes, da Universidade Federal de Campina Grande - UFCG, Campus de Cajazeiras - nos apresenta seu artigo PROBLEMATIZAÇÕES CONSTITUINTES DA JUVENTUDE ESTUDANTIL CONTEMPORÂNEA, parte da pesquisa de pós-doutorado desenvolvido na Faculdade de Educação da Universidade de São Paulo, o qual parte do mapeamento sobre a produção acadêmica acerca da juventude estudantil brasileira na contemporaneidade publicada em periódicos nacionais, buscando compreender o processo de constituição da juventude estudantil nesse discurso acadêmico e tendo Foucault como seu referencial

\begin{tabular}{|l|l|l|l|l|} 
QRovista 2 ialectus & Ano 4 & n. 11 & Agosto - Dezembro 2017 & p. 1-10 \\
\hline
\end{tabular}


teórico. Neste discurso, majoritariamente referente a estudantes de escolas públicas, foram analisados os temas e as problematizações enunciados sobre a juventude estudantil. Nesse sentido, ficou demonstrado que a constituição da juventude estudantil é pautada por tensão e conflitos, principalmente quanto à disciplinarização imposta pela escola e a autonomia desejada pelos jovens estudantes.

No artigo intitulado DISPOSITIVO-BULLYING E GOVERNAMENTALIDADE SECURITÁRIA: DIÁLOGOS COM O PENSAMENTO DE MICHEL FOUCAULT, o autor João Paulo Pereira Barros, da Universidade Federal do Ceará - UFC, tem o intuito de apresentar as conexões entre modos de operação do dispositivo-bullying e as estratégias de governamentalidade neoliberal articuladas a mecanismos de segurança na contemporaneidade, sempre em vista da necessidade de um debate crítico a respeito desse efervescente e contemporâneo tema. O texto, em um primeiro momento, porá em análise a relação entre a consolidação da categoria bullying para dar conta de determinadas modulações de violência entre pares em contextos escolares/educacionais e a emergência das tecnologias biopolíticas de poder características dos dispositivos de segurança. Em um segundo momento, discutirá como certos modos de operação do dispositivo bullying tem oportunizado a intensificação de processos de judicialização da vida, caracterizados pelo enquadramento jurídico-legal cada vez mais minucioso e insidioso das relações sociais no cotidiano.

\section{Em ÉTHOS CRÍTICO E GOVERNAMENTALIDADE EM MICHEL} FOUCAULT, Rogério Luís da Rocha Seixas, Pesquisador-docente convidado do grupo de pesquisa Bildung - IFPR, Instituto Federal do Paraná, trabalha sobre a hipótese do pensamento foucaultiano ter um forte componente de ativismo filosófico, ético e político, descrito como atitude, um éthos, que engloba todo o seu trabalho, mas que se torna mais pungente em sua, assim denominada, última fase ou fase ética, envolvendo a temática da governamentalidade. Partindo desta temática, o artigo discute o vínculo entre ética e política, exatamente por se tratar da ligação entre liberdade, verdade, poder e resistência; destacando-se a relação entre a prática do governo dos outros e o exercício do governo de si. A essas questões é atrelada ainda a análise da articulação entre verdade, ação política e governamento, quando o autor trata de identificar a existência de uma atitude política que ganha o contorno de uma atitude ética em se recusar a ser

\begin{tabular}{|l|l|l|l|l|}
\hline Govista Dialectus & Ano 4 & n. 11 & Agosto - Dezembro 2017 & p. 1-10 \\
\hline
\end{tabular}


governado de tal forma. Trata-se do éthos crítico enquanto prática de liberdade e como forma de recusa ao exercício de governamento excessivo na conduta dos indivíduos.

A professora Cristiane Maria Marinho, ligada à Universidade Estadual do Ceará e à Universidade Federal de Goiás, apresenta o artigo denominado OS LIMITES DE RESISTÊNCIA E PODER NA RELAÇÃO ENTRE DIREITOS HUMANOS E BIOPOLÍTICA. Neste, a professora adota como referências o pensamento dos filósofos Michel Foucault e Giorgio Agamben objetivando produzir uma necessária discussão sobre a questão dos direitos humanos enquanto biopolítica, no tempo presente. É nesta perspectiva que a autora assinala a urgente necessidade de se compreender os poderes contemporâneos na condição de biopolítica e de se pensar as formas possíveis de resistência a tais poderes, situando e analisando de modo bastante pertinente os direitos humanos como uma dessas resistências ao poder e evidencia a importância de se estar atento ao movimento de renovação dos poderes e das resistências e de considerar o caráter agonístico da relação entre biopolítica e direitos humanos.

Em DISCURSO, PODER E SEXUALIDADE EM FOUCAULT, os autores Guilherme Paiva de Carvalho e Aryanne Sérgia Queiroz de Oliveira, da Universidade do Estado do Rio Grande do Norte, analisam os discursos da medicina sobre a transexualidade e a disorder of sex development (DSD) a partir da genealogia das relações de poder de Foucault, particularmente, da perspectiva desse filósofo acerca do poder, do discurso e da sexualidade. Os autores mostram que, ao não se enquadrarem dentro da normatização da ciência médica ocidental, as experiências transexuais são consideradas patológicas, ou ambíguas e anomalias pelos dispositivos de saber-poder heteronormativos. Carvalho e Oliveira apontam que a análise genealógica foucaultiana desse regime de verdade sobre os corpos e as subjetividades transexuais são produtos de uma série de discursos e práticas de poder heteronormativas em torno da sexualidade.

Em A MASTURBAÇÃO NOS LIVROS DIDÁTICOS DE CIÊNCIAS: UMA ANÁLISE A PARTIR DOS CONCEITOS DE BIOLÍTICA E DE DISPOSITIVO DA SEXUALIDADE, a autora Joana Viana de Barros, da Universidade Federal do Estado do Rio de Janeiro (UNIRIO), analisa os livros didáticos de Ciências, segundo os conceitos de biolítica e de dispositivo da sexualidade elaborados por Foucault. A autora lembra que a patologização do jovem masturbador teria tido um papel de destaque na construção do dispositivo da pedagogização do sexo em meados do século XVIII.

\begin{tabular}{|l|l|l|l|l|}
\hline Q Povista Dialectus & Ano 4 & n. 11 & Agosto - Dezembro 2017 & p. 1-10 \\
\hline
\end{tabular}


Todavia, Barros argumenta que o sentido de normalidade atribuído à masturbação nas publicações do último século está associado com a questão da saúde, e não de doença, o que, segundo a autora, demonstra uma mudança do regime de verdade contemporâneo.

Os professores Marcelo Rito, da Escola Waldorf Rudolf Steiner, e Julio Groppa Aquino, da Universidade de São Paulo, no artigo intitulado BIOPOLÍTICA E ESCOLA MODERNA: apontamentos para um debate, mobilizam a noção foucaultina de estatização do biológico para pensar a díade biopolítica-escolarização e centram as suas análises sobre as práticas educacionais como estratégias da biopolítica na vigência dos anos 1920 e 1930 no Brasil com a emergência do pensamento escolanovista. Os autores também assinalam a importância e a possibilidade de se sobrepor ao binarismo poder/resistência, direcionando o pensamento para os processos de veridicção e de subjetivação, haja vista em tais processos ser possível pensar a patologização das dificuldades escolares e a questão do condicionamento do desenvolvimento biológico às estratégias de autogoverno.

Raquel Célia S. Vasconcelos, professora da Faculdade Metropolitana da Grande Fortaleza e do Instituto Federal de Educação, Ciência e Tecnologia do Ceará, no artigo intitulado A JUSTIÇA POPULAR E SEUS ATOS JURÍDICOS: O TRIBUNAL E SEUS REGIMES DE VERDADE NA (DES)QUALIFICAÇÃO DAS SUBJETIVIDADES, tomando como referências teóricas o pensamento de Michel Foucault, Hannah Arendt e Walter Benjamin, pensa a justiça popular e seus atos jurídicos conduzidos pelo tribunal e seus regimes de verdade considerando tal justiça como representante dos interesses da classe dominante, haja vista o seu processo de legitimação da relação direito-justiça no seu exercício de poder. Assim, a autora argumenta que o poder e a biopolítica separam as vidas que devem ser cuidadas e as vidas de parte da população que devem ser colocadas fora da jurisdição humana, cuja violência sofrida não constitui violação.

No artigo O SUJEITO DA FILOSOFIA É PRODUTO OU PRODUTOS DA HISTÓRIA? REFLEXÕES ENTRE KANT E FOUCAULT, Felipe Figueiredo de Campos Ribeiro, da Universidade Federal do Rio de Janeiro (UNIRIO), discute a ambivalência atividade/passividade, intrínseca ao sujeito histórico, que marca o pensamento ético e político do último Foucault. Ao confrontar Kant e Foucault, Ribeiro evidencia o impasse contemporâneo para a compreensão do sentido do processo

\begin{tabular}{|l|l|l|l|l|}
\hline Govista Dialectus & Ano 4 & n. 11 & Agosto - Dezembro 2017 & p. 1-10 \\
\hline
\end{tabular}


histórico. Para Kant, a História consistia de um movimento ativo e para frente, enquanto para Foucault, este movimento oscilava entre à passividade e à atividade.

Erenildo João Carlos, da Universidade Federal da Paraíba (UFPB), em ACHADOS SOBRE A NOÇÃO ARQUEOLÓGICA DO DISCURSO EM FOUCAULT, parte dos textos de Foucault, produzidos nas décadas de 1960 e 1970, para refletir sobre entendimento arqueológico de Foucault sobre o discurso. O autor identifica um "giro arqueológico" em Foucault, fundamental para se entender a abordagem da Análise Arqueológica como uma Teoria do Discurso.

O artigo intitulado SEMIÁRIDO: UMA PERSPECTIVA GENEALÓGICA escrito pelas professoras Mariana Moreira Neto e Maria Lucinete Fortunato, ambas da Universidade Federal de Campina Grande, campus de Cajazeiras, centra-se em descrições e importantes análises acerca do Semiárido nordestino a partir do emprego das noções de discurso e relações de saber-poder, conforme a concepção foucaultiana. As autoras buscam, desse modo, compreender a produção de visibilidades e dizibilidades nas relações de poder/saber das políticas públicas de educação, da educação do campo, do protagonismo de jovens assentados e de mulheres apenadas, problematizando a ideia de convivência com o semiárido a partir das posições de sujeitos, regimes de verdade e a positividade de discursos/saberes, na perspectiva da diversidade e das múltiplas subjetividades. Concluem as autoras que a ideia de convivência com e no semiárido é constituída a partir de produção discursiva que exercita relações de poder e de saber.

Inaugurando a seção fluxo contínuo temos $\mathrm{o}$ artigo DIREITO, INTERPRETAÇÃO E MARXISMO: UMA ANÁLISE A PARTIR DE LUKÁCS do professor Vitor Sartori da Universidade Federal de Minas Gerais (UFMG). Levando em consideração a questão do papel ativo do jurista na conformação objetiva do Direito, o autor pretende traçar um panorama geral acerca do modo como a filosofia marxista, vista através da figura de Lukács, pode se colocar frente ao desenvolvimento da teoria e da filosofia do Direito contemporâneos, os quais se diferenciam do positivismo exegético e do formalismo normalmente atribuídos ao tratamento dogmático do campo jurídico. O objetivo de Sartori é mostrar que Lukács leva em consideração aspectos importantes do "terreno do Direito", aspectos estes os quais destacam-se na teoria do Direito contemporâneo e que nem sempre são tidos em conta pelos marxistas.

\begin{tabular}{|l|l|l|l|l|}
\hline Q Povista Qialectus & Ano 4 & n. 11 & Agosto - Dezembro 2017 & p. 1-10 \\
\hline
\end{tabular}


Dando prosseguimento aos artigos inseridos em nosso fluxo contínuo, apresentamos o texto escrito pelos autores Frederico Costa (UECE), Antônio Marcondes (UFC), Karla Raphaella (UECE) e Eduardo Chagas (UFC/CNPq) intitulado: CATEGORIA DA TOTALIDADE EM HISTÓRIA E CONSCIÊNCIA DE CLASSE DE GYÖRGY LUKÁCS: UMA APROXIMAÇÃO ÀS QUESTÕES DE MÉTODO NO MARXISMO. O escrito expõe uma aproximação à categoria de totalidade na obra História e consciência de classe do filósofo húngaro György Lukács. O objetivo do artigo é expor o desenvolvimento da categoria de totalidade para o filósofo húngaro e, assim, aclarar o método dialético, além de outras categorias que fundamentam o marxismo.

O professor Vilson da Mata da Universidade Federal do Paraná (UFPR) nos apresenta o texto: SOBRE A POLÍTICA NA IDEOLOGIA ALEMÃ DE MARX E ENGELS. Esse texto tem como objetivo mostrar a estruturação do método materialista dialético, o debate com os contemporâneos mais representativos de Marx e Engels e a análise de um contexto indicativo de possíveis mudanças radicais na sociedade do século XIX. Assim Da Mata expõe o duplo caráter da política que se expressa, ao mesmo tempo, como uma positividade, posto ser uma instância confirmadora do humano, construída historicamente a partir da atividade produtiva; e como uma negatividade, uma vez que assume o caráter de irracionalidade ao negar o humano.

Em AS DESAVENTURAS DA DEMOCRACIA - UM OLHAR CRÍTICO SOBRE BREXIT, LE PEN E TRUMP a professora Marta Nunes da Costa da Universidade Federal do Mato Grosso do Sul (UFMTS) tem como finalidade nos desvelar como a democracia está em crise e ninguém parece contestar esse fato. $\mathrm{O}$ problema que se levanta é de que forma agir diante dos vários acontecimentos políticos que parecem ter marcado uma tendência no paradigma democrático do Ocidente. $\mathrm{O}$ artigo de Marta da Costa nos oferece uma leitura possível para compreender a nossa condição presente a partir de um olhar crítico sobre as os resultados políticos do Brexit, a ascenção de Le Pen e a vitória de Trump nas últimas eleições presidenciais.

O professor Juliano Oliveira, pós-doutorando da Universidade Federal do Piauí (UFPI), abrilhanta esta edição da Revista Dialectus com o texto ENTRE O LIBERALISMO E O REPUBLICANISMO: HABERMAS E A DEMOCRACIA DELIBERATIVA. O artigo enfatiza o conceito de democracia deliberativa proposto por

\begin{tabular}{|l|l|l|l|l|}
\hline Qovista Dialectus & Ano 4 & n. 11 & Agosto - Dezembro 2017 & p. 1-10 \\
\hline
\end{tabular}


Jürgen Habermas. A democracia deliberativa habermasiana, segundo Oliveira, conserva os momentos positivos do liberalismo e do republicanismo, ao mesmo tempo em que supera aquilo que considera negativo tanto de um como de outro. É a partir da síntese entre liberalismo e republicanismo que Habermas articulará seu conceito de democracia deliberativa, haja vista que ambas as tradições, segundo Habermas, são insuficientes para pensarmos as demandas políticas contemporâneas, conclui o autor.

Evanildo Cotéski, professor da Universidade Federal do Ceará (UFC), nos apresenta seu artigo intitulado: AS RELIGIÕES COMO FORCES PROFONDES NAS RELAÇÕES INTERNACIONAIS. No texto em questão, Cotéski utiliza o conceito de forces profondes, desenvolvido pelo historiador francês Pierre Renouvin, para falar da influência das religiões nas Relações Internacionais. É verdade, assinala Cotéski, que Renouvin considerava ser praticamente impossível compreender historicamente o sagrado religioso. Todavia, como salientou Robert Frank, ao se falar da religião, não se deve focar apenas no aspecto transcendental da fé. A religião faz parte da cultura humana e, como tal, não pode ser desprezada pelo historiador das Relações Internacionais. O conceito de force profonde pode representar a religião de forma positiva ou negativa. Na presente análise, Cotéski, buscará salientar os valores positivos e universais das religiões.

O último artigo da seção fluxo contínuo traz a pesquisa dos professores Antônio Roberto Xavier (UNILAB), Edilberto Cavalcante Reis (UECE) e Eduardo Chagas (UFC/CNPq) intitulada CULTURA E EDUCAÇÃO NA IDADE MÉDIA: ASPECTOS HISTÓRICO-FILOSÓFICO-TEOLÓGICOS. O objetivo desta pesquisa visa ratificar epistemologicamente a desmistificação convencional sobre a Idade Média como sendo a "Idade das Trevas". Para tanto, elencaram-se como categorias principais de análise a cultura e a educação nesse período histórico, é o que enfatizam os autores.

Ao apresentarmos os artigos que compõem a décima primeira edição da Revista Dialectus; é importante salientarmos, que o modo caranguejo do método foucaultiano, tal como o próprio filósofo o denomina, traduz a ausência de linearidade temática deste dossiê. Há tanto a abordagem metodológica do pensamento foucaultiano, quanto a abordagem problematizadora sobre a constituição da juventude estudantil contemporânea brasileira, estendendo-se até a discussão sobre o dispositivo-bullying e

\begin{tabular}{|l|l|l|l|l|}
\hline Govista Dialectus & Ano 4 & n. 11 & Agosto - Dezembro 2017 & p. 1-10 \\
\hline
\end{tabular}


sua relação com a governamentalidade securitária, ambas em diálogo vivo com o pensamento de Michel Foucault.

A discussão sobre a governamentalidade também está presente ao ser discutida em sua relação com um éthos crítico enquanto prática de liberdade e como recusa ao exercício de governamento excessivo na conduta dos indivíduos, bem como na discussão sobre os limites de resistência e poder na relação entre direitos humanos e biopolítica.

A patologização como categoria central e determinante nos processos de subjetivação e sexualidade também se encontra presente relacionada à transsexualidade, à patologização das dificuldades escolares e à ideia de masturbação presente nos livros didáticos de ciências. Em toda essas discussões em torno da patologização se encontra atravessada uma análise a partir dos conceitos de biolítica e de dispositivo da sexualidade.

A clássica e decisiva relação foucaultiana saber-poder-discurso-verdade também marca algumas das seguintes discussões desenvolvidas no presente dossiê relacionadas aos seguintes temas: processo de legitimação da relação direito-justiça e as vidas válidas ou não; confronto teórico entre Kant e Foucault; reflexão sobre o entendimento arqueológico de Foucault sobre o discurso; e, por fim, análise sobre a convivência com e no semiárido nordestino brasileiro.

Em tempos de Projeto como o Escola sem Partido (EsP), é importante mostrar suas relações existentes com uma biopolítica neoliberal, apresentando as características neoliberais presentes na tecnologia do biopoder, na sua pretensão de controlar a educação escolar, visando determinar currículo, conteúdo, orientação sexual, ideologia, moral, religião e política conforme os interesses do capital e de uma conduta acrítica que o favoreça, e cerceando, desse modo, a liberdade das discussões e da autonomia do professor em sala de aula.

Em Foucault, a produção de individualidades possibilitada pelo poder não repressivo, e sim produtivo, fabrica um indivíduo que não é meramente passivo, sobre o qual se exerce o poder, mas que também exerce poder. Este exercício do poder consiste em uma produção de indivíduos que podem ser gerenciados, em suas conduções, por intermédio de uma governamentalidade biopolítica, na qual o poder, com suas tecnologias, se exerce sobre a vida, fazendo viver ou deixando morrer os indivíduos que

\begin{tabular}{|l|l|l|l|l|}
\hline Q Povista Qialectus & Ano 4 & n. 11 & Agosto - Dezembro 2017 & p. 1-10 \\
\hline
\end{tabular}


compõem uma população. Aquela produção de indivíduos está diretamente ligada à produção de saber, ou seja, os indivíduos são produzidos conforme a produção de saberes que, por sua vez, conjuntamente, indivíduos e saberes, realizam a intervenção do poder nos processos econômicos do capitalismo.

Essa nova modalidade de tecnologia de poder, não repressiva e produtiva, que é a Biopolítica, que deixa morrer e faz viver, lança mão do exercício da norma e do controle como estratégias de poder sobre a população. E é nesse âmbito que o Estado, como peça fundamental nesse exercício do poder sobre a vida, se torna racista. E daí Foucault falar em Racismo de Estado, o qual determina quem será deixado à própria sorte para morrer ou quem será levado a continuar vivendo. E compreenda-se aí a morte não somente como fenômeno biológico, mas também como exclusão. São a partir dessas práticas sócio-raciais, presentes nas tecnologias de exercício do biopoder de racismo de Estado, que o movimento Escola sem Partido é compreendido, aqui, como um Racismo de Estado da educação. Diante desse quadro conceitual, é possível observar como a Biopolítica neoliberal está presente no EsP.

Nessa conjuntura da atual política brasileira, é necessaário afirmar que a alma desse Projeto Escola sem Partido lança suas garras para além da escola, quando há um recrudescimento de posições reacionárias em todos os âmbitos da vida, há a patologização dos prazeres e de tudo o que afirma a vida. Daí compreendermos que o presente dossiê se justifique a partir dos seguintes motivos: ao chamar a atenção para a necessária saúde da vida (Nietzsche); ao discutir as atuais formas de exercício de poder e, assim, possibilitar pensar novas formas de resistências e de contracondutas; ao fazer uma filosofia que seja uma crítica do presente e não só discussão de categorias que se tornam meros exercícios mentais que podem se traduzir como outra forma de poder reforçando a realidade identitária; ao compreender que a morte de Dandara foi um assassinato espetacularizado pela miséria do presente e que se traduz em muitas formas de mortes que acontecem todo dia e a qualquer hora e em todo lugar do cotidiano biopolítico em que vivemos. Ou morremos?

\begin{tabular}{|l|l|l|l|l|}
\hline Govista Dialectus & Ano 4 & n. 11 & Agosto - Dezembro 2017 & p. 1-10 \\
\hline
\end{tabular}

